\title{
Influence of forage availability on feeding station behaviour of ewes
}

\author{
C Roguet $1,2, \mathrm{~S}$ Prache 2 \\ IINRA, LAHM, Theix, 63122 St-Genès-Champanelle ; 2IRGM, CRA Toulouse, 31326 Castanet Tolosan, France
}

The grazing process can be considered on the basis of three spatiotemporal scales : bite selection and formation, feeding station utilization and patch selection (Demment and Laca 1993, World Conf on Anim Prod, Edmonton, Canada, 439-460). The objective of the present study is to better understand feeding station (FS) utilization and selection, particularly feeding station residence time (FSRT) and moving between feeding stations.

Evolution of FS behaviour was studied during the grazing down process of a reproductive cocksfoot sward (flowerheads appeared). The experiment was conducted from 25 may to 20 june 1994 on a 0.12 -ha paddock rotationally grazed by 11 Romanov * Limousine dry ewes. Sward surface height (SSH) decreased with time from 373 to $76 \mathrm{~mm}$. Foraging behaviour was measured on 5 ewes three times weekly. Each animal was video recorded one after the other in a predetermined order during 5 minutes and four times during the evening meal. Then we encoded steps and head position to determine FS and moving type. We defined FSRT as the time intervals between two successive steps except i) those during which animal kept its head up and ii) those shorter than $1 \mathrm{~s}$ considered as only travelling.

Total time spent at FS remained constant and represented about $97 \%$ of recording time : sheep were feeding actively and moving was limited during recording periods (evening meal). Mean FSRT decreased curvilinearly with time from $11.1 \mathrm{~s}$ to $7.3 \mathrm{~s}$. FSRT were distributed into the following classes: from 1 to $2 \mathrm{~s}, 2$ to $10 \mathrm{~s}, 10$ to $20 \mathrm{~s}$ and greater than $20 \mathrm{~s}$. The contribution of each class to the total recording time was significantly modified as the trial progressed (chi-square test) : it increased for 2-10 s stations, decreased for more than $20 \mathrm{~s}$ stations and remained stable for the other ones (table).

The numbers of FS visited and of steps with the head down (SHD) per min increased with time up to day 19 then remained constant (respectively 5.2 to $8.4 \mathrm{FS} / \mathrm{min}$ and 6.8 to 11.5 $\mathrm{SHD} / \mathrm{min}$ ). SHD between stations remained stable at 1.3-1.4. Number of steps with the head up (SHU) per min was constant up to day 19 then fell sharply. Contribution of SHU to total step number (SHU/S) fell from 33 to $6 \%$ with time.

As the grazing down progressed, FS behaviour changed : FSRT decreased, FS/min increased and moving was modified. Total moving increased but contribution of moving head up (generally corresponding to long movings) decreased especially at the end of the use of the paddock. FSRT and moving between FS will be further analyzed through foraging activity, particularly the number of bites prehended and the succession of events (FSmoving). First viewings of videotapes indicate that at the beginning of the trial, sheep exploited a few long stations separated by few SHD and by long movings head up. At the end, FS were rapidly depleted and abandoned; sheep selected contiguous FS, head down, with rare long movings.

\begin{tabular}{|c|c|c|c|c|c|}
\hline Day & 2 & 5 & 11 & 19 & 23 \\
\hline $\mathrm{SSH}(\mathrm{mm})$ & 363 & 337 & 300 & 124 & 98 \\
\hline $\begin{array}{l}\text { FSRT (s) } \\
\text { contribution of FSRT classes }\end{array}$ & $11.1 \pm 0.5(\mathrm{se})$ & $8.8 \pm 0.3$ & $8.0 \pm 0.3$ & $6.9 \pm 0.2$ & $7.3 \pm 0.2$ \\
\hline to recording time (\%) $1-2 \mathrm{~s}$ & 2.1 & 2.6 & 2.7 & 3.1 & 2.0 \\
\hline $2-10 \mathrm{~s}$ & 19.7 & 31.4 & 36.5 & 49.2 & 49.3 \\
\hline $10-20 \mathrm{~s}$ & 30.5 & 32.5 & 31.3 & 28.6 & 35.9 \\
\hline$>20 \mathrm{~s}$ & 42.4 & 27.9 & 21.9 & 12.8 & 9.4 \\
\hline $\mathrm{FS} / \mathrm{min}$ & $5.2 \pm 0.3(\mathrm{se})$ & $6.5 \pm 0.3$ & $7.3 \pm 0.7$ & $8.4 \pm 0.7$ & $8.1 \pm 0.4$ \\
\hline $\mathrm{SHD} / \mathrm{min}$ & $6.8 \pm 0.6(\mathrm{se})$ & $8.9 \pm 0.1$ & $9.9 \pm 0.8$ & $11.5 \pm 0.3$ & $10.5 \pm 1.3$ \\
\hline $\mathrm{SHU} / \mathrm{min}$ & $3.5 \pm 0.8(\mathrm{se})$ & $3.2 \pm 1.1$ & $3.8 \pm 1.1$ & $3.7 \pm 1.5$ & $0.9 \pm 0.5$ \\
\hline
\end{tabular}

